\title{
XIAP Antisense Oligonucleotide AEG35156
}

National Cancer Institute

\section{Source}

National Cancer Institute. XIAP Antisense Oligonucleotide AEG35156. NCI Thesaurus.

Code C49180.

A second-generation synthetic antisense oligonucleotide with potential antineoplastic activity. AEG35156 selectively blocks the cellular expression of X-linked inhibitor of apoptosis protein (XIAP), a pivotal inhibitor of apoptosis that is overexpressed in many tumors. This agent reduces total levels of XIAP in tumor cells, working synergistically with cytotoxic drugs to overcome tumor cell resistance to apoptosis. XIAP interferes with both the intrinsic and extrinsic program-death signaling pathways, which may render tumor cells resistant to apoptosis. 